\title{
UAV- based Photogrammetry and Geocomputing for Hazards and Disaster Risk Monitoring - A Review
}

\author{
Christopher Gomez ${ }^{1,2^{*}}$ (D) and Heather Purdie ${ }^{1}$
}

\begin{abstract}
Background: The unraveling of the human-induced climate-change crisis has put to the forth the ability of humanbeings to impact the planet as a whole, but the discourse of politics has also emphasized the ability of the human race to adapt and counterweigh the environmental change, in turn increasing the public expectation that one should be able to control nature and its affects. Such cozy and reassured society consequently puts an increasing amount of pressure on hazards assessors, emergency and disaster managers "to get it right", and not only to save the majority, but to save all. To reach such level of competency, emergency relief teams and disaster managers have to work always faster with an increasing need of high quality, high-resolution geospatial data. This need is being partly resolved with the usage of UAV (Unmanned Autonomous Vehicles), both on the ground and airborne.

Results: In this contribution, we present a review of this field of research that has increased exponentially in the last few years. The rapid democratization of the tool has lead to a significant price reduction and consequently a broad scientific usage that have resulted in thousands of scientific contributions over the last decade. The main usages of UAVs are the mapping of land features and their evolution over time, the mapping of hazards and disasters as they happen, the observation of human activity during an emergency or a disaster, the replacement of telecommunication structures impacted by a natural hazards and the transport of material to isolated groups.

Conclusion: Those usages are mostly based on the use of single UAVs or UAVs as single agents eventually collaborating. The future is most certainly in the ability to accomplish complex tasks by leveraging the multiple platforms possibilities. As an example, we presented an experiment showing how multiple UAV platforms taking imagery together at the same time could provide true 4D (3D in time) of geo-processes such as river-bed evolution, or rockfalls, etc.
\end{abstract}

Keywords: UAV, Drone, Disaster, Natural hazards, Disaster risk, Geotechnical monitoring, Disaster management framework

\section{Introduction}

At the end of 2015, the COP21 in Paris ended with a series of more or less binding agreements, which received large media coverage because of the increasing sense of urgency that has emerged over the last few years. In this context of accelerating climate change that will continue exacerbating existing weather hazards and disaster risk, Japan, countries of Western Europe and North America are also experiencing a major demographic shift as the baby-boomers are hitting retirement age (MacKellar,

\footnotetext{
* Correspondence: christopher2501@gmail.com

'Department of Geography, University of Canterbury, Christchurch, New Zealand ${ }^{2}$ Kobe University, Faculty of Maritime Sciences, Kobe, Japan
}

2004). This environmental and human shift is going to have tremendous effects on the sciences: how many researchers can a society afford, what research can be funded and what should be prioritized. In a country like Japan, where the external debt has reached 2.8 trillion US dollars in 2014, the number of children does not meet the generation renewal with only 1.4 children per couple. On the contrary, the 65 years old and more already account for $25 \%$ of the population, and their number is growing. This shift will have important consequences on what countries can afford, and ultimately it will impact the fields of pure and applied sciences as we know them.

Because of those imperatives, the development of automated solutions to reduce the needs of human resources is essential, and so are the development in robotics and 
artificial intelligence (Gomez et al. (2015a); Gomez et al., 2016), including the usage of UAVs (Unmanned Aerial Vehicles) for hazards, disaster risk and emergency management. Despite the eventual difficulties to fund research and sciences and consequently the potential reduction of human resources, the governmental obligations to survey and protect population against environmental hazards remain unchanged, and most probably so will the expectations of citizen.

Within this framework, the present contribution will provide a non-exhaustive review of the usage of UAVs in three key areas of geological risk-related geosciences - earthquakes, volcanic activity and landslides. In the discussion, we also present some of the expected future developments, and particularly, the usage of multiple UAVs in swarms for photogrammetry in $4 \mathrm{D}$.

Unmanned Aerial Vehicle (UAV) is also referred to as Unpiloted Aerial Vehicle and Remotely-Piloted Aircraft (RPA). To qualify in this category the flying aircraft must be without any pilot on board and it has to be reusable. Despite of appearances, UAV isn't new and the first one was flown as early as 1918 in the USA as a pilotless flying bomb: the Kettering Bug (Gillespie, 2009). As it lacked the artificial intelligence, or the control link with a pilot on the ground, it reached a given destination by using a set of propeller rotation and a gyroscope. Therefore, the evolution of UAVs over the 20th century and the early 21st hasn't been about the concept of flying vehicles without pilots, but the possibility to control them with more accuracy and have them more autonomous.

In recent years, such research and the decreasing price of electronic components have allowed the commercialization of "straight from the shelves" solutions that can be flown by the public, generating a market worth 5,400 million Euros in 2013 alone (Colomina and Molina, 2014). The evolution of onboard computing and ground connection also permits the accomplishment of complex tasks (Maza et al., 2011) and semi-autonomous flight (Rathbun et al., 2002), which in turn has led to the development of applications for industrial monitoring with UAV - e.g. (Hausamann et al., 2005) - and environmental and engineering structures monitoring with UAV - e.g. (Gonzales-Jorge et al., 2014).

In the same fashion, the versatility of UAVs can provide support for hazard assessment and emergency management - e.g. Quadritsch et al., 2010 - at both the local and the regional scale, depending on the usage of different platforms (Fig. 1).

At the local or site scale, helicopter and multi-rotor systems are best adapted, as most of the commercial solutions have a range of up to $\sim 2 \mathrm{~km}$ corresponding to flight times of $15 \mathrm{~min}$ (some large platform can fly up to an hour but they remain costly) and they allow stationary flight over precise site or the investigation of local site with complex vertical extensions, such as cliffs, rockfall walls, etc. (The Press, 2014). At the regional scale, the use of fix-wings is more appropriate and allows the coverage of large areas over short period of time, for the survey of volcanic eruption, fire evolution. For fix-wings, different companies offer several "from the shelf" solutions that cost up to 50-80 k. US\$, from which more expensive custom solutions can also be purchased. This high versatility, relatively low-cost, the availability of "easy-to-fly" platforms and the possibility to multiply the frequency of flights over time has led to a real boom of UAVs in disaster risk reduction (Fig. 2). The number of publications on UAVs and disasters has exploded from none in 2000 to 81 in a single year in 2014. This growth follows an increasing interest for the field, with 6 publications in 1990 on UAVs that peaked in 2014 to 2164 (as per Scopus search).

UAVs have imposed their presence in the field of hazards, disaster risk and emergency management, because of their recent price decrease but also because onboard electronic is now advanced enough to provide semi-controlled pilot systems and aided-pilot controls, in such a way that

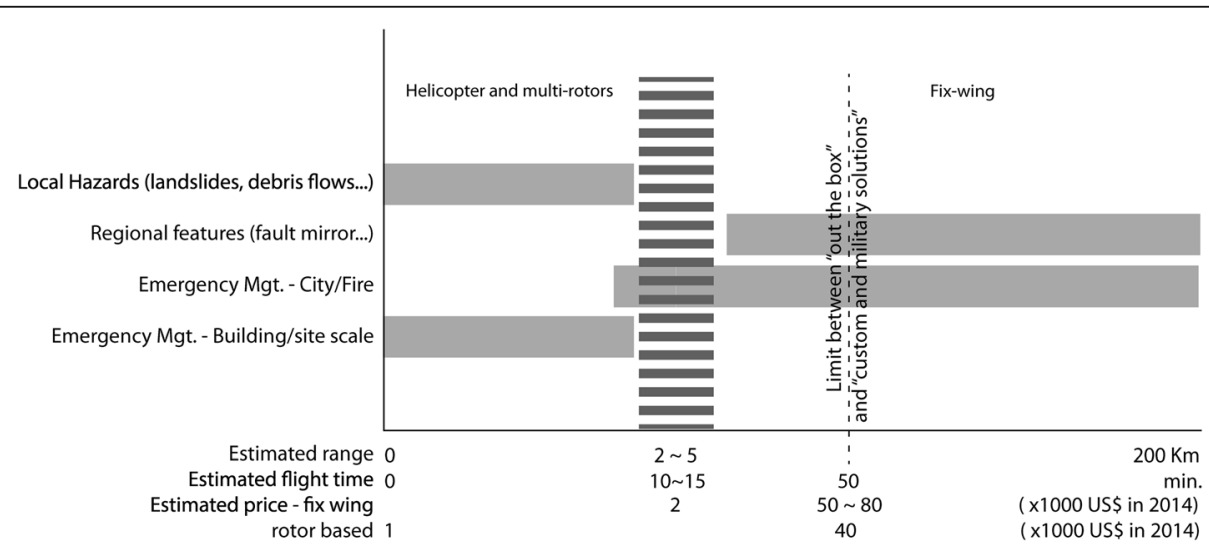

Fig. 1 Rotor-based and fix-wing solutions for hazards to emergency management. The operation range and types calls for different solutions requiring different levels of funding 



Fig. 2 Number of references about UAV, drones, hazards, disaster and emergency from Scopus search (another table about UAS and its usage in commercial and military purposes can be found in Colomina and Molina 2014:80)

non-specialists can operate them. This development translates in term of scientific interests with 434 entries under "UAV and Disaster" in scopus (as per December 2015), 166 entries for "UAV and Hazard" and 87 entries for "UAV and Emergency management".

A review of the recent contributions published in the last few years (Table 1) show that the research field is interested by the usage of UAVs in area that are difficult to access, and also as a temporary replacement of local infrastructure (like cellphone towers). Another type of research has been more interested in capturing spatial data by rigging different sensors to the flying platforms (Table 1).

\section{Review}

Structure-from-Motion Photogrammetry from UAVs for hazards, disaster risk and emergency management

One of the sensors commonly rigged to the UAV is a camera or a video camera, fixed by a gimbal to limit the vibration and the effects of rolling of the UAV. Such configuration has seen a real boom in the field of geosciences in recent years, because of its very low-cost, high versatility and provides the possibility to calculate 3D models using the Structure from Motion (SfM) algorithm (Clapuyt et al., 2015; Hugenholtz et al. 2013). Structure from Motion or Structure and Motion is traditionally part of the research field of close-range photogrammetry. The SfM algorithm has been developed in the engineering field of computer vision in the 1970s (Ullman, 1979), and it has benefited of the development of pose-estimation and bundle adjustment (Hartley and Wisserman 2004) and image matching
(Furukawa and Ponce 2010). At the same time, the everincreasing computing capacities and the number of "readysolutions" have made the method very popular, and allowed the development of specific solutions (Table 1).

Although the combination of SfM with airborne photography is mostly used as a low-cost replacement to LiDAR (Light Detection And Ranging), it can also be used to work from historical data, providing 3D dataset of periods when laser technologies were not existing and computing in its infancy - 1940s or 1950s for instance - (Gomez et al. (2015b)). Furthermore, the possibility to use nadir photographs combined with photographs taken from different angles allows the detailed recording of subvertical surfaces and cavities as well (Gomez and Kato, 2014).

The main appeal of SfM combined with UAVs is the ability to run the data collection for a very low-cost on a platform that is easy to transport (in a backpack) and that can be launched from virtually any site. The data processing has also been facilitated by the development of numerous proprietary or open-source software that offers the non-specialist the ability to recreate 3D models.

\section{Data collection}

Despite the use of gimbal to stabilize the camera, the aircraft movements, or the time to resolve focal or any unintended movement due to wind turbulence for instance can result in blur photographs. Usable photographs are therefore not equal to the number of photographs taken. Results from personal unpublished work has provided an average of $72 \%$ of usable images for data taken from a small quadcopter 
Table 1 Recent studies in UAVs and hazards, disaster risk and emergency management, showing the main research directions

\begin{tabular}{|c|c|c|c|c|c|c|c|c|c|c|}
\hline \multirow[t]{2}{*}{$\mathrm{Nb}$. } & \multicolumn{2}{|l|}{ Type } & \multirow{2}{*}{$\begin{array}{l}\text { Hazard } \\
\text { Assessment }\end{array}$} & \multirow{2}{*}{ Vulnerability } & \multirow[t]{2}{*}{ Emergency } & \multirow{2}{*}{$\begin{array}{l}\text { Disaster } \\
\text { Recovery }\end{array}$} & \multirow{2}{*}{$\begin{array}{l}\text { (A)pplied } \\
\text { (T)est; (Th)ory }\end{array}$} & \multirow{2}{*}{$\begin{array}{l}\text { Hazard } \\
\text { Denomination }\end{array}$} & \multirow[t]{2}{*}{ Key concepts } & \multirow[t]{2}{*}{ References } \\
\hline & rotor & $\overline{\text { Fix-wing }}$ & & & & & & & & \\
\hline 1 & $x$ & $x$ & & & $x$ & & $T$ & & $\begin{array}{l}\text { Mapping; Compared fixed wings against multirotor \& rapid } \\
\text { photogrammetry processing against precise slow method. }\end{array}$ & Boccardo et al. (2015) \\
\hline 2 & $x$ & & & & $x$ & & Th & & $\begin{array}{l}\text { Discuss the use of UAV in disasters and accident as a new } \\
\text { frontier in human activity observations and provide } \\
\text { technical developments }\end{array}$ & $\begin{array}{l}\text { Choi and Lee (2011), Di Franco } \\
\text { and Salvatori (2015) }\end{array}$ \\
\hline 3 & $x$ & & & $x$ & $x$ & & $\mathrm{~T}, \mathrm{Th}$ & & $\begin{array}{l}\text { Use UAVs as telecommunication relay replacement in } \\
\text { disaster impacted areas/simulation of network } \\
\text { efficiency }\end{array}$ & $\begin{array}{l}\text { Bupe et al. (2015), Dalmasso et al. } \\
\text { (2012), Tuna et al. (2014) }\end{array}$ \\
\hline 4 & & $x$ & & & $x$ & $x$ & $\mathrm{~T}, \mathrm{~A}$ & Earthquake & $\begin{array}{l}\text { UAV photogrammetry at different altitude for Sichuan } \\
\text { Earthquake Recovery Mgt }\end{array}$ & Merdaway and Guvenc (2015) \\
\hline 5 & & $x$ & $x$ & $x$ & $x$ & & A & Flood & $\begin{array}{l}\text { Urban flood mapping using random forest algorithm } \\
\text { from UAV acquired data }\end{array}$ & Xie et al. (2014), Feng et al. (2015) \\
\hline 6 & & & $x$ & & $x$ & & T & & $\begin{array}{l}\text { Real time mapping and communication with authorities } \\
\text { for hazard and emergency mapping }\end{array}$ & Suzuki et al. (2008) \\
\hline 7 & $x$ & & & $x$ & $x$ & $x$ & Th & & Food and relief material transport & Nedjati et al. (2016) \\
\hline 8 & $x$ & & & $x$ & & $x$ & Th, $T$ & Earthquake & $\begin{array}{l}\text { Use photographs and pointclouds acquired from the } \\
\text { ground and UAV to detect earthquake impacts on } \\
\text { buildings }\end{array}$ & Vetrivel et al. (2015) \\
\hline 9 & & $x$ & $x$ & $x$ & & $x$ & A & $\begin{array}{l}\text { Landslides and } \\
\text { debris flows }\end{array}$ & $\begin{array}{l}\text { Use of a fix-wing based imagery for post-landslide } \\
\text { and debris-flow }\end{array}$ & Liu et al. (2015) \\
\hline 10 & & & & $x$ & & $x$ & A & & $\begin{array}{l}\text { UAV-based imagery to monitor change in different } \\
\text { environments including post-disaster }\end{array}$ & Ezequiel et al. (2014) \\
\hline
\end{tabular}


with a standard deviation of almost $26 \%$, depending on the type of surface, wind speed, luminosity. Data present in the literature also reflect a similar pattern with photographs usable for photogrammetry representing 30\% to $90 \%$ (Fig. 3). It therefore pays to increase the number of planned photographs by almost two folds to be absolutely certain to capture the necessary data. Such strategy is reflected in the disparity of photographs used and the area analyzed (please note that the flying altitude are all similar, as the objectives to capture land movements were all similar, regardless of the area investigated). This disparity calls for the creation of protocols of data collection, in order to homogenize existing dataset and increase the possibility of comparisons between the different data collections.

\section{Assessing the quality of results}

The quality of DEMs and DSMs produced using the SfM method using UAV is traditionally done using the RMSE (Root Mean Square Error) method, which is assessed using known points on the ground, which are calculated either using laser technologies such as the terrestrial laser scanner (Obanawa et al., 2014) or Survey Grade Global Navigational Sattelite System (Turner et al., 2015). As the 3D pointcloud created by $\mathrm{SfM}$ is constrained using Ground Control points (GCPs), authors have used part of them as check-points. Turner have used 30\% of the GCPs as check points and obtained a largest RMSE of 0.076 to 0.09 respectively horizontally and vertically. The quality of the results is difficult to interpret as it depends on the number of images, the distance of the camera to the object and the characteristics of the field data. Moreover, the variation tends to locally follow either a positive trend or a negative trend, resulting in local over-estimation in $\mathrm{z}$ or a local under-estimation. Some work has shown a variation of $\pm 2 \mathrm{~m}$ for a surface of $200 \mathrm{~m} \times 200 \mathrm{~m}$ (Westoby et al., 2012). They have also recorded the uncertainty with the GCPs themselves. For their field research in Wales, they recorded an average uncertainty in xyz of $0.003 \mathrm{~m}$, while in Nepal they recorded an uncertainty of $0.226 \mathrm{~m}$.

The high variability in the data collection is directly related to the issues raised with the data collection process, which needs to be streamlined in the field of geosciences, especially because the methods is being used in numerous areas such as earthquake, volcanic and landslides sciences.

\section{UAVs and geo-hazards: earthquakes, volcanic eruptions and landslides}

One should argue that earthquakes, volcanic eruptions and landslides aren't the only geo-hazards, but they are arguably the fields where the majority of UAV-related research has been progressed over the last decades, especially in the field of visual monitoring and photogrammetry.

\section{UAVs and earthquakes}

The spatio-temporal frequency of damaging earthquakes has, up to date, restricted the use of UAVs to postearthquake research and work, but UAVs provide a precious post-earthquake survey tool to collect perishable data, especially for building that aren't safe to approach or inspect (Mitsuhito et al., 2015; Meyer et al., 2015).
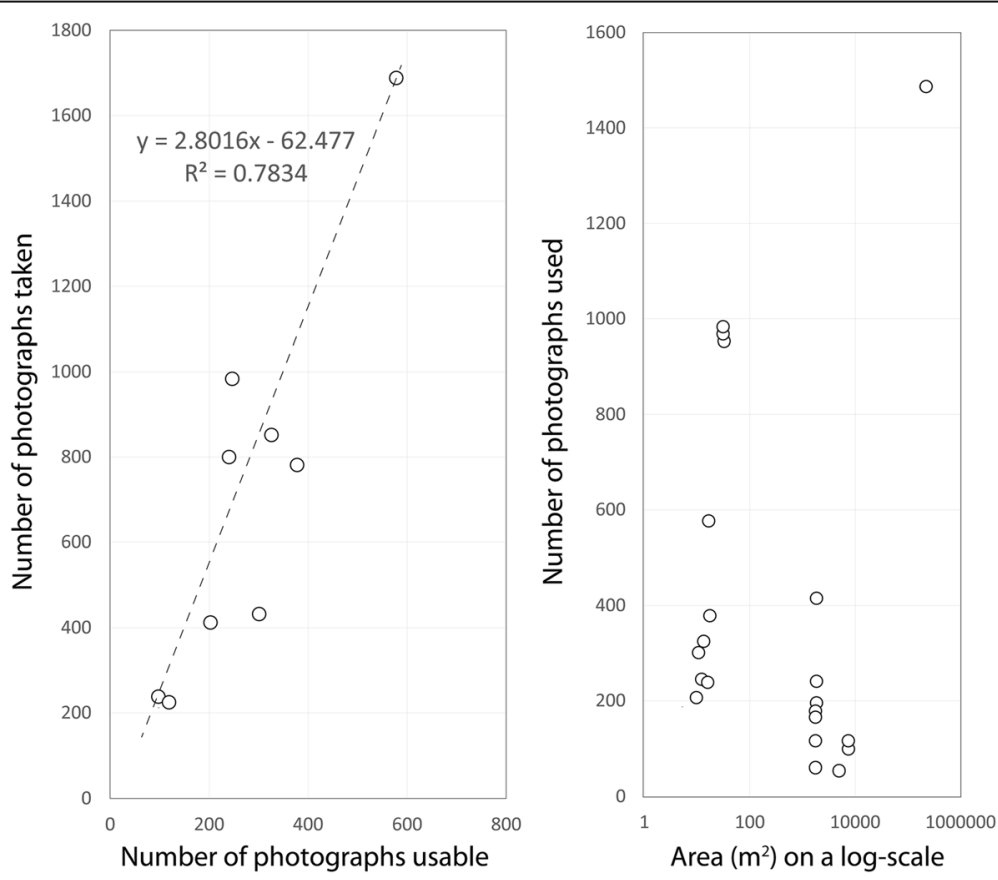

Fig. 3 Relation between photographs their usability and the survey area 
UAVs are a complement to larger manned-aircraft photography and photogrammetry, because they can provide rapid solutions with virtually no infrastructure, like airport and airspace control. UAVs are also ideal to detect small-scale changes and cracks in buildings and on the ground. Indeed, low-cost solution UAVs usually can't cover large areas, but they provide a different dataset with an increased resolution. This pattern was demonstrated during the recent Kumamoto earthquake in South Japan (Kyushu Island), in the aftermath of which the authorities used small UAVs to survey the surface rupture of the fault (https://youtu.be/DXTAAvVB2M8). The authorities of Japan also used UAVs to evidence historical building impacts that are difficult to see from a traditional aircraft, such as collapsed walls and structure with large trees around obstructing the nadir view (https://youtu.be/BcWlJN9lnHs). Images captured from UAVs can then easily converted into 3D models. In the aftermath of L'Aquila earthquake in Italy, the state of the build environment was evaluated using UAV combined with the photogrammetric method of SfM (Dominici et al., 2016). UAV-based imagery can also be the source of more complex remote sensing methodologies to determine the impacts of earthquakes (Shaodan et al., 2015). The use of UAVs also goes beyond visual observations. In the Fukushima area for instance, the Japanese authorities have used UAVs to fly above and around the Fukushima power plant in order to measure radiation levels. It can be also used for the delivery of emergency goods, such as medical products (Thiels, 2015), but also food and other vital items, especially when roads and other communication infrastructures have been profoundly damaged (Nedjati et al., 2016).

\section{UAVs and active volcanoes}

Active and erupting volcanoes is an area of geosciences that has seen further development for the use of UAVs. Erupting volcanoes present numerous challenges to data collection. Sarah P. Williams wrote "In 1984, the volcano Mauna Loa erupted in Hawaii, sending ribbons of lava winding down its slopes. Geologist and former pilot David Pieri of the California Institute of Technology's Jet Propulsion Laboratory wanted to get measurements and observation of every part of the lava flow to predict its ultimate route and length. However, he only had one way to see the lava: with a helicopter. "I remember being so frustrated because you could only see what was right in front of you," says Pieri. "It was a $22-\mathrm{km}$ lava flow and by the time we flew to the bottom, we had no idea what was going on at the top" (Williams, 2013). This introductory comment epitomizes the difficulties of working on active volcanoes, where researchers can often be at harm's way (e.g. the Unzen killed the Kraft husband and wife during the 1991-1995 eruption and 41 other TV crews and scientists).
The problems solved by UAV therefore concerns keeping scientists and researchers at a reasonable distance from danger, with duties spanning from visual observation of disasters (Sato and Nakanishi, 2014), measure of evolution from visual imagery and photogrammetry (Nakano et al., 2014), gas sampling (Mori et al., 2016), to sediment sampling using robotic sampling devices (Yajima et al., 2014).

UAVs are thus useful for collecting gas emanation above volcanoes, where flying in a manned-aircraft near the ground might be too hazardous, especially when heat creates strong turbulences. For instance, researchers have used a fix-wing UAV to collect $\mathrm{SO} 2$ gas emission over Kirishima Volcano in South Japan (Shinohara, 2013), a multi-rotor to collect plume data during the $2014 \mathrm{Mt}$. Ontake eruption (Mori et al., 2016), different fix-wings and balloons at Costa Rica Volcano (Diaz et al., 2015).

The overwhelming majority of active volcanoes are located around the Ring Of Fire, with Japan and Indonesia being the two countries with the world highest numbers of active volcanoes. Along island arcs, volcanoes can thus often be at sea or in areas difficult to access. In such cases, UAVs have a strategic advantage as they can be operated remotely from floating platforms and boats. In Japan, Nishinoshima Volcano (Ogasawara Island group), which has emerged from the sea in November 2013 and has seen continuous eruption since, is a perfect example of a volcano at sea, where coasting is difficult and dangerous, and for which UAV monitoring has yield relative success. The Geospatial Information Authority of Japan has conducted a series of UAV flights departing from nearby Chichijima (GSJ, 2015), and used acquired visible imagery with SfM in order to produce 3D maps of the area over time to monitor the evolution of the volcano (Nakano et al., 2014).

UAVs in volcanic research have therefore been an extension of present activities, enabling safer data collection and easier data collection in remote areas. One can foresee that future development in this area should involve multiple aircrafts flying simultaneously, in order to improve the spatial distribution in time of phenomena that evolve rapidly, such as ash plumes for instance. A great advance in ash plume morphology simulation would be the collection of simultaneous photographs from swarms of UAVs, in order to collect the shape of ash plumes (or pyroclastic flow elutriated ash-clouds) in 4D (3D over time).

\section{UAVs and landslides}

A field strongly contributed by change monitoring from UAV is landslide research. Landslide monitoring necessitates measures of the rate of surface change, such as fracture openings (Niethammer et al., 2010; Stumpf et al., 2013), as well as differential measures of vertical and horizontal movements, in order to understand their mechanics (Akca. 2013; Dewitte et al., 2008). For slow-onset mass movements - i.e. compared to velocities at which we and our technology 
moves - the measure of change over time can be performed from one single UAV over several years. The monitoring of those events is essential, especially because landslides produce casualties and important economic impacts every year (Schuster, 1996).

Consequently, the combination of photogrammetric methods and UAVs allow a high frequency revisit of landslide sites, providing the necessary data to create DSMs and DEMs, which allow the calculation of modification of the position of volumes and masses on a slope, as well as changes in topography (Marek et al., 2015). Results accuracy and precision are however still compared to GNSS data or other geomatic devices, in such a way that the method isn't absolutely free from ground-truthing.

Evolution monitoring is also controlled by the rate of evolution/change in a landslide. Indeed, a location that moves very quickly will display important change in between two seasonal survey for instance, whereas other landslides might only show very limited change over the same period of time. The measured change has to be bigger than the error produced by the measurements, or in other words, one must choose the survey parameters based on the rate of change of the landslide compared to the field survey frequency for significant results. At the Super-Sauze landslide (France), average velocity of the mass movement ranged between $0.01 \mathrm{~m} /$ day to $0.1 \mathrm{~m} /$ day for the period May 2007 to Oct. 2008. This yearly measure was supported by data of RMSE $=0.31 \mathrm{~m}$ between the two surveys (Niethammer et al., 2012). Using a similar method on a landslide in the Zlinsky region (Czech Republic), the $\mathrm{RMSE}_{\mathrm{z}}$ was also of similar value with $0.33 \mathrm{~m}$ (Marek et al., 2015), and the authors only used change value over the survey period that are greater than the RMSE, with value exceeding $8 \mathrm{~m}$ change over the period 2008-2013.

UAV monitoring of hazards and disaster sites is therefore a promising tool that has been rising in the last decade, but it is still constrained by (1) weather conditions and daylight conditions; (2) by the need of photogrammetric methods to still have some ground control points to reach maximum accuracy; (3) by the technical limitations, such as range, flying capacities, etc., and also more recently (4) UAV aviation laws due to the important rise of the drones. To complement this rapid review, the second section of the present contribution provides a series of example applications of photogrammetry and UAVs before providing some insights about what the author thinks is the future of the research field.

\section{Multiscale integrated systems for hazard monitoring and crisis management in Japan}

For natural hazards, risk, disaster and emergency management, Japan is certainly one of the best-prepared countries in the world, with efforts at different levels including the integration of UAV technology in their framework. UAVs are powerful platform to collect data for hazard assessment on their own, but also to bridge gaps between different survey methods and provide extra-layer of information (Fig. 4). In order to provide information to managers and the different authority levels, Japan has the Geospatial Authority of

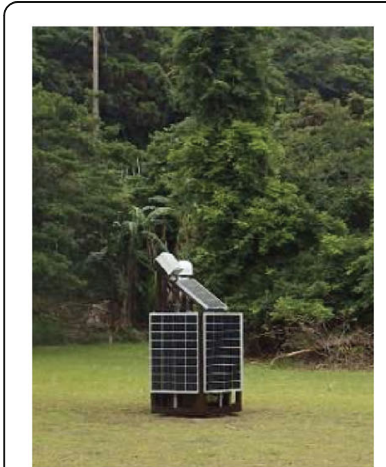

GNSS monitoring system for volcanic deformation: REGMOS

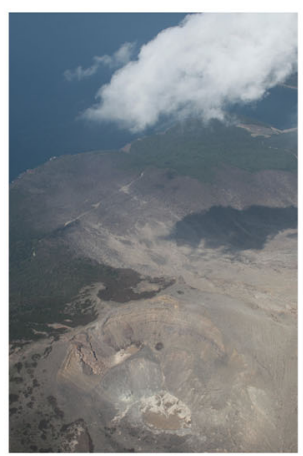

UAV

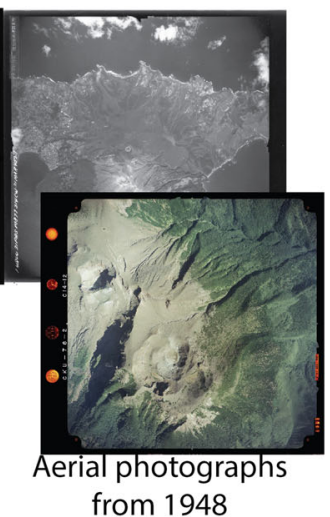

from 1948

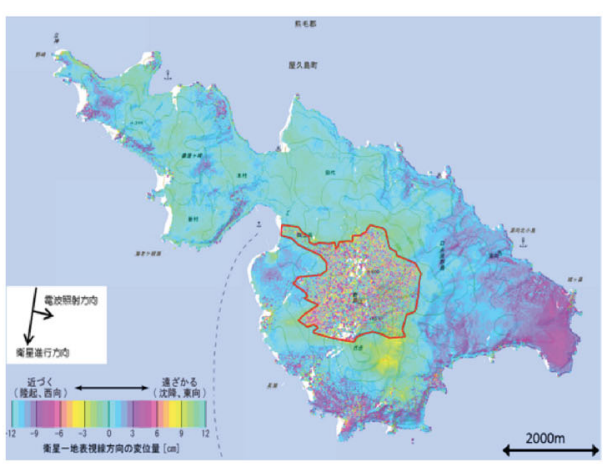

Radar interferometry from SAR data to measure land surface change

Fig. 4 Technological framework for hazards and risk monitoring for crisis management in low-density and remote areas of Japan - in this case the Kuchinoerabujima in South Japan. The system encompasses an array of tools offering different frequency of data collection at different spatial scales. The data is then fed back to practitioners and decision makers 
Japan, which holds GIS data for the country and a stock of aerial imagery, including a section dedicated to hazards and disaster management. As part of their activity, they provide free of charge for non-commercial activity a set of data that includes ground station monitoring (weather or seismicity for instance), traditional aerial photographs of an area, satellite interferometry data, to which they have added in the recent years imagery from a custom long-range $2 \mathrm{~m}$ wingspan fix-wing UAV.

\section{Discussion}

UAVs have brought a lot of change to the field of natural hazards, disaster risk management, emergency and safety operation. The UAVs can be divided between long-range capabilities - dominated by fix wings -, and short-range "higher-precision" missions at the site level (fleet dominated by quadcopters in the second case). The choice of one type of engine over another can be guided by the following checklist:

- What is the size of the area that needs to be investigated? This will determine the type of UAV to be used.

- What precision, accuracy, type of data is needed? This will control the degree of overlaps between photographs and the altitude of flight, and also the type of camera, in turn influencing the type of UAV needed.

- What are the physical constraints of the landscape? This will control the choice of using an autopilot or a fully manual flight, the type and location of take off and landing.

- What is the location of the survey and the type of weather? Strong winds are usually difficult to handle with quadcopters, and fix-wing aircrafts can handle faster wind speeds.

Once an operator has worked through this generic checklist, it is then possible to look at the details of specific flights, and how different methods can be combined, in order to produce the desired data. Indeed, for disaster management, the combination of the different UAV types with associated photogrammetry and automation can provide rapid, if not immediate data, on a situation, which in turn improves the decision making process, especially with the help of photogrammetric methods that do not need ground control [59]. The actual level of automation of those flights, and the potential for further development makes UAVs a robust tool to help fighting the challenges of climate change and aging economies.

The mobility and ability of different types of UAVs to reach disaster impacted areas is of particular importance, because very often disaster impacted areas experience lifeline disruptions, including transport infrastructures (Berariu et al., 2015). In such case, UAVs can also carry relief aid for instance. Fikar et al. (2016) have shown that UAVs were particularly adequate for 'the last-mile' delivery and that coordinated efforts could improve the delivery of relief through multipoints transport (Fikar et al., 2016). The authors have however emphasized that complex organized systems still need improvement as disaster-impacted areas holds a lot of unknown variables, which are difficult to predict.

Further combination of the dataset presented in this contribution can also increase the capacities of UAVbased solution. Two directions those research can take, is the usage of UAV-based SfM for emergency services on collapsed buildings and the acquisition of 4D imagery using swarms of vehicles.

\section{UAV-based SfM for emergency services working on collapsed buildings}

The exponential growth of articles on UAVs and emergency management has put the emphasis on the versatile aspects of UAV for first responders in disasters area. In the case of large earthquakes in city areas, numerous types of building collapses results in a variety of post-collapse 'topography', which can inform the severity or the necessity to act in one part of a city or another (Pham et al., 2014). New development in the automated recognition of direct threats in disaster areas, such as fires for instance now allow automated UAVs to operate in even more complex situations (Cook et al., 2015).

It is expected that future research in structural engineering and the 3D modelling of buildings before and after collapses should provide sufficient data on the location of pockets and gaps, where search and rescue should concentrate their efforts. UAVs should be able to locate eventual gaps by comparing the 3D dataset after collapse with a precollapse model of the building as well as the distribution of mass in a building, after which search activity can be concentrated on.

As part of a fully integrated data infrastructure for risk and disaster management, like the one developed in Japan, a first automated layer should provide disaster and emergency responders with the location of the geographical areas where relief is needed (Shaodan et al., 2015), and then on the individual site a second type of UAV work should provide sufficient details on the collapsed structure, in order to increase the chances to find survivors. Consequently, there is a need to integrate UAVs into the disaster management framework, but also to integrate different types of UAVs to operate at different scales and level of precision. Fix-wing platforms are certainly ideal to work at several kilometers scale, and rotorbased platform are certainly most indicated for small sites, where hoovering flights might be necessary.

Such work can then be extended to situations where a disaster is unfolding, and for which swarms of UAVs are necessary, in order to capture the data in 4D (3D over time). 


\section{Acquisition of 4D imagery using swarms of UAVs for emergency management}

Over the last few years, the development of wireless sensor networks has provided the possibility to track movements and change in space, adding time-stamp to otherwise simple snapshot of the environmental. Combined with UAVs, such technology is allowing collaborations of sensors between UAVs and the ground (Rathbun et al., 2002), as well as the flight of swarms of collaborative UAVs that can be used for emergency management (Bupe et al., 2015). In disaster-impacted areas, clusters of UAVs have proven to be able to replace communication towers that would have been brought down by a disaster (Dalmasso et al., 2012; Merdaway and Guvenc 2015; Tuna et al., 2014) and also provide imagery for any post-disaster activity (Quadritsch et al., 2010). At the convergence between this development and the SfM method that I presented earlier, there is a new forthcoming development: real-time 4D evolution of features or 3D over time. Like traditional SfM can recreate in 3D a disaster zone, either at the building scale (Vetrivel et al. 2015) by taking a series of photographs from one camera, a swarm of vehicle can take a series of photographs from multiple-cameras at the same time. If the cameras are all synchronized, then it is possible to take photographs at a given rate and thus reconstruct the $3 \mathrm{D}$ environment over time, in order to see how a disaster environment evolves.
During rescue operations for instance, this would be an invaluable tool to monitor the evolution of a collapsed building for instance. In order to test this idea, the author has conducted a laboratory experiment for which he has used a series of 8 rigged Go-pro cameras triggered by one remotecontrol. The test was carried out over an evolving riverbed while the water flows using a $200 \mathrm{~cm} \times 80 \mathrm{~cm}$ river-table. The experiment has proven that the technique was working (Fig. 5), although the vertical RMSE was $2 \mathrm{~cm}$ (for a vertical variability of $10 \mathrm{~cm}$ ). This high variability is linked to the lack of cameras available for the experiments, and that limit the quality that the SfM algorithm produces.

Nevertheless, results in Fig. 5 clearly shows that a swarm of vehicles equipped with similar cameras have the ability to recreate series of 3Ds over a time period.

\section{Conclusion}

Although UAV technology has only hit the commercialshelves in the last few years, its already relative low-cost and broad availability is expected to further its rapid expansion providing communities and emergency services the chance to add this tool for use in disaster areas - and not being limited to scientific use. In the present contribution, we reviewed the use of UAVs for hazards, disaster risk and emergency management, as well as the use for three of the most important geo-hazards: earthquakes, volcanic activity

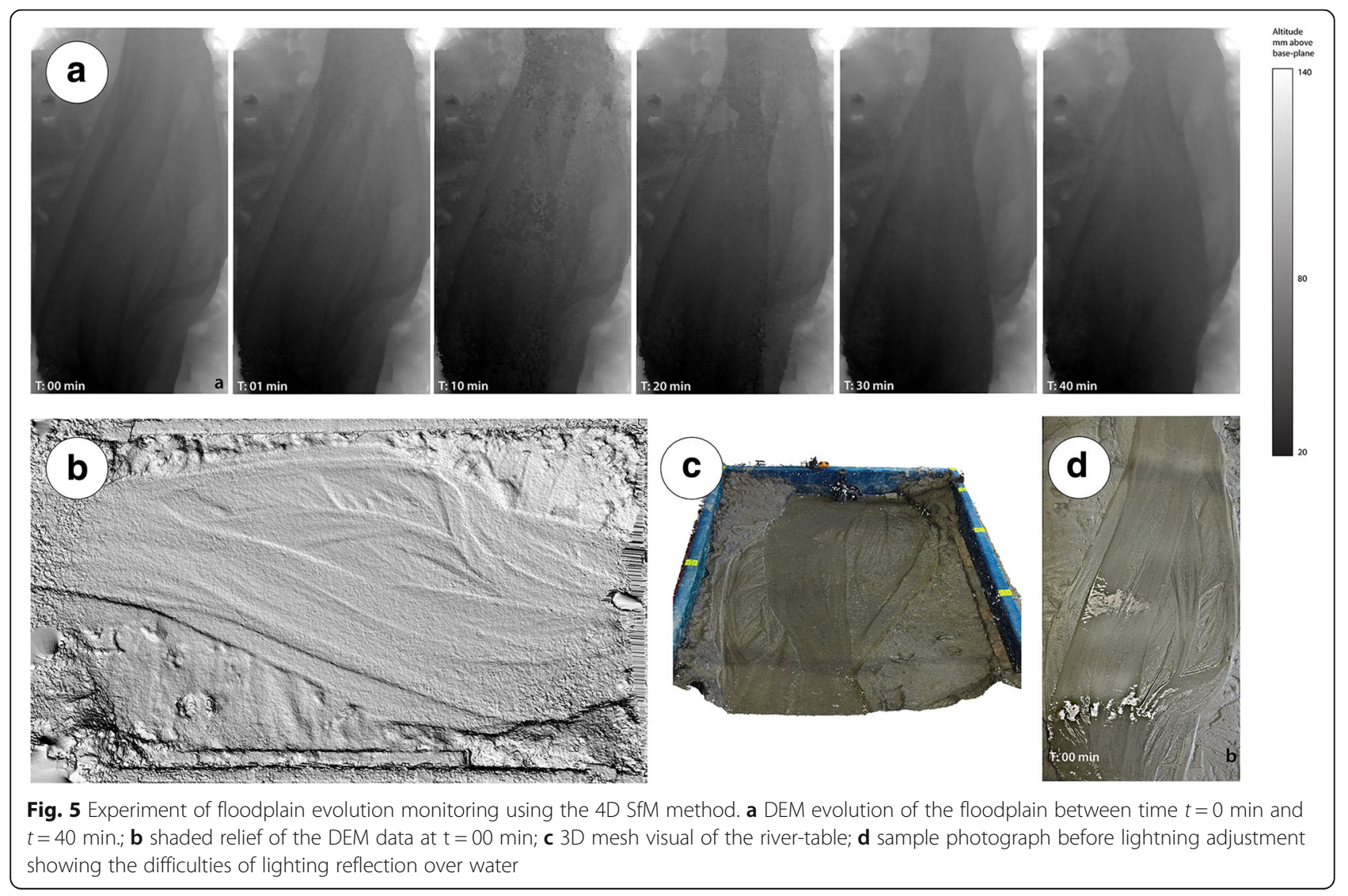


and landslides. These three examples have emphasized the connection between survey-scales (time and space) and the scales of phenomena. The use of UAV is constrained by the predictability of events and their duration. Consequently, UAVs have been used in the aftermath of earthquakes for emergency management purposes, because earthquakes are highly unpredictable in time. It has been used in both emergency management and hazards and risks monitoring on volcanoes, because volcanic eruptions are much more predictable and last for periods of time that allow the deployment of one to several flights during its activity period. Finally, landslides are usually sloweronset events (not all though), which have offered the scientists the opportunity to do repeat flights over periods of months to years, from which the evolution of the landslide surfaces can be examined.

The natural next step in combined photogrammetry with UAVs - I think - is the development of swarms of vehicles that can work collaboratively, in order to capture rapid changes in 3D. For instance sea-waves or rockfalls have never been measured in 3D. There are numerous reconstruction based on one or several cameras using algorithms, but real 3D in time (or 4D measures) haven't been performed yet and could be very important to better understand physical processes in geosciences.

\section{Acknowledgment}

The author would also like to thank the editors for inviting this present contribution.

\section{Authors' contribution}

CG authored the article and lead the research project the present publication is part of. HP contributed to the field work and the data creation for the present publication. She also helped improve the manuscript. Both authors read and approved the final manuscript.

\section{Competing interests}

The authors declare that they have no competing interests.

Received: 18 August 2016 Accepted: 18 November 2016

Published online: 25 November 2016

\section{References}

Akca, D. 2013. Photogrammetric monitoring of an artificially generated shallow landslide. The Photogrammetric Record 28: 496-501.

Berariu, R., C. Fikar, M. Gronalt, and P. Hirsch. 2015. Understanding the impact of cascade effects of natural disasters on disaster relief operations. Int. J. Dis. Risk Red. 12: 350-356. http://dx.doi.org/10.1016/j.jidrr.2015.03.005.

Boccardo, P., F. Chiabrando, F. Dutto, F. Giulio Tonolo, and A. Lingua. 2015. UAV Deployment Exercise for Mapping Purposes: Evaluation of Emergency Response Applications. Sensors 15: 15717-15737.

Bupe Jr. P., Haddad, R., Rios-Gutierrez, F. 2015. Relief and Emergency Communication Netowrk Based on an Autonomous Decentralized UAV Clustering Network. Proceedings of the IEEE SoutheastCon

Choi, K., Lee, I. 2011. A UAV Based Close-range Rapid Aerial Monitoring System for Emergency Response. International Archives of the Photogrammetry, Rem. Sens. Spat. Info. Sc. XXXVIII-1/C22

Clapuyt, F., V. Vanacker, and K. Van Oost. 2015. Reproducibility of UAV-based earth topography reconstructions based on Structure-from-Motion algorithms. Geomorphology 260: 4-15. doi:10.1016/j.geomorph.2015.05.011.

Colomina, I., and P. Molina. 2014. Unmanned aerial systems for photogrammetry and remote sensing: A review. ISPRS Journal of Photogrammetry and Remote Sensing 92: 79-97.
Cook, Z., Zhao, L., Lee, J., Yim, W. 2015. Unmanned Aerial System for First Responders. Proceedings of the 12th International Conference on Ubiquitous Robots and Ambient Intelligence (URAI): 306-310. Doi:10.1109/URAl.2015. 7358959.

Dalmasso, I., Galletti, I., Giuliano, R., Mazzenga, F. 2012. WiMAX networks for emergency management based on UAVs. IEEE First AESS European Conference on Satellite Telecommunication (ESTEL) Proceeding: 1-6

Dewitte, O., J.C. Jasselette, Y. Cornet, M. Van Den Eeckhaut, A. Collignon, J. Poesen, and A. Demoulin. 2008. Tracking landslide displacements by multitemporal DTMs: A combined aerial stereophotogrammetric and LIDAR approach in western Belgium. Engineering Geology 7: 582-586.

Di Franco, S., and R. Salvatori. 2015. Current situation and needs in man-made and natech risks management using Earth Observation techniques. Rem. Sens. Appl. Soc. Env. 1: 72-84.

Diaz, J.A., D. Pieri, K. Wright, P. Sorensen, R. Kline-Shoder, C.R. Arkin, M. Fladeland, G. Bland, M.F. Buongiorno, C. Ramirez, E. Corrales, A. Alan, O. Alegria, D. Diaz, and J. Linick. 2015. Unmanned Aerial Mass Spectrometer Systems for In-Situ Volcanic Plume Analysis. Journal of the American Society for Mass Spectrometry 26: 292-304. doi:10.1007/s13361-014-1058-x.

Dominici, D., Alicandro, M., Massimi, V. 2016. UAV photogrammetry in the postearthquake scenario: case studies in L'Aquila. Geomatics, Nat. Hazards Risk: 117. doi: $10.1080 / 19475705.2016 .1176605$

Ezequiel, C.A.F., Cua, M., Libatiquem, N.C., Tangonan, G.L., Alampay, R., Labuguen, R.T., Favila, C.M., Honrado, J.L.E., Canos, V., Devaney, C., Loreto, L.B., Bacusmo, J., Palma, B. 2014. UAV Aerial Imaging Applications for Post-Disaster Assessment, Environmental Management and Infrastructure Development. 2014 International Conference on Unmanned Aircraft Systems (ICUAS) Orlando, Fl, USA proceedings: 274-283.

Feng, Q., J. Liu, and J. Gong. 2015. Urban Flood Mapping Based on Unmanned Aerial Vehicle Remote Sensing and Random Forest Classifier - A case of Yuyao, China. Water 7: 1437-1455.

Fikar, C., M. Gronalt, and P.A. Hirsch. 2016. decision support system for coordinated disaster relief distribution. Exp. Syst. Appl. 57: 104-116. http://dx. doi.org/10.1016/j.eswa.2016.03.039.

Furukawa, Y., and J. Ponce. 2010. Accurate, dense, and robust multiview stereopsis. IEEE Transaction in Pattern Analysis and Machine Intelligence 32: 1362-1376.

Gillespie, P.G. 2009. Weapons of Choice: The Development of Precision Guided Munitions (2). Tuscaloosa: University of Alabama Press.

Gomez, C., Kato, A. 2014. Multi-scale voxel-based algorithm for UAV-derived point-clouds of complex surfaces. IEEE International ICARES - Aerospace Electornics and Remote Sensing Technology: 205-209.

Gomez, C., Oguchi, T.; Evans, I. 2015(a). Spatial Analysis in Geomorphology (1): Present Directions from Collection to Processing (Editorial). Geomorphology 242: 1-2

Gomez, C., Hayakawa, Y., Obanawa, H. 2015(b). A study of Japanese landscapes using Structure from Motion derived DSMs and DEMs based on historical aerial photographs: New opportunities for vegetation monitoring and diachronic geomorphology. Geomorphology 242: 11-20

Gomez, C., T. Oguchi, and I. Evans. 2016. Quantitative Geomorphology with Geographical Information Systems (GIS) for Evolving Societies and Science (Editorial). Geomorphology 260: 1-3.

Gonzales-Jorge, H., I. Puente, D. Roca, H. Martinez-Sanchez, B. Conde, and P. Arias. 2014. UAV Photogrammetry Application to the Monitoring of Rubble Mound Breakwaters. J. Perform. Constr. Fac. 04014194: 1-8.

GSJ. 2015. Eruption of the 29 May 2015 at Kuchinoerabujima. Report of the Geological Society of Japan, https://www.gsj.jp/hazards/volcano/kazanbukai/yochiren/kuchinoerabu_20150827_1.pdf (in Japanese). Accessed 19 Nov 16.

Hartley, R.I., Wisserman, A. 2004. Multiple View Geometry in Computer Vision. Cambridge: Cambridge University Press.

Hausamann, D., W. Zimig, G. Schreier, and P. Strobl. 2005. Monitoring of gas pipelines - a civil UAV application. Aircr. Eng. Aerosp Tec. 77: 352-360.

Hugenholtz, C.H., K. Whitehead, O.W. Brown, T.E. Barchyn, B.J. Moorman, A. LeClair, K. Riddell, and T. Hamilton. 2013. Geomorphological mapping with a small unmanned aircraft system (sUAS): Feature detection and accuracy assessment of a photogrammetrically-derived digital terrain model. Geomorphology 194: 16-24.

Liu, C.-C., Chen, P.-L., Tomoya, M., Chen, C.-Y. 2015. Rapidly responding to landslides and debris flow events using a low-cost unmanned aerial vehicle. J. Rem. Sens. 9: doi:10.1117/1.JRS.9.096016 
MacKellar, L. 2004. Economic impacts of population ageing in Japan. Edward Elgar Pub

Marek, L., J. Miřijovský, and P. Tuček. 2015. Monitoring of the Shallow Landslide Using UAV Photogrammetry and Geodetic Measurements. Eng. Geol. Soc. Ter. 2: $113-116$

Maza, I., F. Caballero, J. Capitan, J.R. Martinez-de-Dios, and A. Ollero. 2011. Experimental Result in Multi-UAV Coordination for Disaster Management and Civil Security Applications. Journal of Intelligent and Robotic Systems 61: 563-585.

Merdaway, A., Guvenc, I. 2015. UAV Assisted Heterogeneous Networks for Public Safety communications. IEEE Wireless Communications and Networking Conference Workshop - 2nd International Workshop on Device to Device and Public Safety Communications: 1-6.

Meyer, D., M. Hess, C. Lo, C.E. Wittich, T.C. Hutchinson, and F. Kuester. 2015. UAVbased Post Disaster Assessment of Cultural Heritage Sites Following the 2014 South Napa Earthquake. IEEE Digital Heirtage 2: 421-424. doi:10.1109/ DigitalHeritage.2015.7419539.

Mitsuhito, H., Yong, Y., Zuo, Z., Kamat, V.R., Zekkos, D., Lynch, J. 2015. Implementation of UAV localization methods for a mobile post-earthquake monitoring system. IEEE EESMS: 66-71. Doi: 10.1109/EESMS.2015.7175854

Mori, T., Hashimoto, T., Terada, A., Yoshimoto, M., Kazahaya, R., Shinohara, H., Tanaka, R. 2016. Volcanic plume measurements using a UAV for the 2014 Mt. Ontake Eruption. Earth Planets Space: 68-49. DOI: DOI 10.1186/s40623-016-0418-0

Nakano, T., I. Kamiya, M. Tobita, J. Iwahashi, and H. Nakajima. 2014. Landform Monitoring in Active Volcano by UAV and SFM-MVS technique. ISPRS XL-8: 71-75. doi:10.5194/isprsarchives-XL-8-71-2014.

Nedjati, A., Vizvari, B., Izbirak, G. 2016. Post-earthquake response by small UAV helicopters, Nat. Hazards 80: 1669-1688. Doi: http://dx.doi.org/10.1007/ s11069-015-2046-6

Niethammer, U., M.R. James, J. Rothmund, J. Travelletti, and M. Joswig. 2012. UAVbased remote sensing of the Super-Sauze landslide: Evaluation and results. Engineering Geology 128: 2-11.

Niethammer, U., Rothmund, S., James, M.R., Travelletti, J., Joswig, M. 2010. UAVbased remote sensing of landslides. Proceedings of the International Archives of Photogrammetry, Remote Sensing and Spatial Information Sciences: 496-501

Obanawa, H., Y. Hayakawa, and C. Gomez. 2014. 3D Modelling of inaccessible Areas using UAV-based Aerial Photography and Structure from Motion. Transactions of the Japanese Geomorphological Union 35: 283-294.

Pham, T.-T.-H., P. Apparicio, C. Gomez, C. Weber, and D. Mathon. 2014. Towards a rapid automatic detection of building damage using remote sensing for disaster management. The Haiti earthquake. Dis. Prev. Manage. 23: 53-66. doi: 10.1108/DPM-12-2012-0148.

Quadritsch, M., K. Kruggl, D. Wischounig-Strucl, S. Bhattacharya, M. Shah, and B. Rinner. 2010. Networked UAVs as aerial sensor network for disaster management applications. Elektr. Inform. 127: 56-63.

Rathbun, D., Kragelund, S., Pongpunwattana, A., Capozzi, B. 2002. An evolution based path planning algorithm for autonomous motion of a UAV through uncertain environments. IEEE Proceedings of the 21st Digital Avionics Systems Conference 8.D.2: 1-12.

Sato, A., Nakanishi, H. 2014. Observation and Measurement in Disaster Areas Using Industrial Use Unmanned Helicopters. IEEE ISSSR: 1-5. Doi: 10.1109/ SSRR.2014.7017671

Shaodan, L., T. Hong, H. Shi, S. Yang, M. Ting, L. Jing, and X. Zhihua. 2015. Unsupervised Detection of Earthquake-Triggered Roof-Holes from UAV Images Using Joint Color and Shape Features. IEEE Geosc. Rem. Sens. 12 1823-1827. doi:10.1109/LGRS.2015.2429894.

Shinohara, H. 2013. Composition of volcanic gases emitted during repeating Vulcanian eruption stage of Shinmoedake, Kirishima volcano, Japan. Earth, Planets and Space 65: 667-675. doi:10.5047/eps.2012.11.001.

Schuster, R.L. 1996. Socioeconomic significance of landslides. In Landslides Investigation and Mitigation; Turner, A.L., Schuster, R.L., Eds. 12-35.

Stumpf, A., J.-P. Malet, N. Kerle, U. Niethammer, and S. Rothmund. 2013. Imagebased mapping of surface fissures for the investigation of landslide dynamics. Geomorphology 186: 12-27. doi:10.1016/j.geomorph.2012.12.010.

Suzuki, T., Miyoshi, D., Meguro, J., Amano, Y., Hashizume, T., Sato, K., Takiguchi, J. 2008. Real-time Hazard Map Generation Using Small Unmanned Aerial Vehicle. SICE Annual Conference 2008, The University ElectroCommunication, proceedings 443-446.

2014 Drones Film Earthquake Damage. Online newspaper - http://www.stuff.co.nz/ the-press/news/hills-and-harbour/9768731/Drones-film-earthquake-damage. (Accessed 19 Nov 2016).
Thiels, C.A. 2015. Use of unmanned aerial vehicles for medical product transport. Air Medical Journal 34: 104-108. 1067991X14003332.

Tuna, G., B. Nefzi, and G. Conte. 2014. Unmanned aerial vehicle-aided communication system for disaster recovery. Journal of Network and Computer Applications 41: 27-36.

Turner, D., A. Lucieer, and S.M. de Jong. 2015. Time Series Analysis of Landslide Dynamics Using and Unmanned Aerial Vehicle (UAV). Remote Sensing 7: 1736-1757. doi:10.3390/rs70201736.

Ullman, S. 1979. The interpretation of visual motion. MIT Press Series in Artificial Intelligence. Cambridge, Massashusets, London, England: MIT Press.

Vetrivel, A., M. Gerke, N. Kerle, and G. Vosselman. 2015. Identification of damage in buildings based on gaps in 3D point clouds from very high resolution oblique airborne images. ISPRS J. Photogramm. Rem. Sens. 105: 61-78.

Westoby, M.J., J. Brasington, N.F. Glasser, M.J. Hambrey, and J.M. Reynolds. 2012. 'Structure-from-Motion' photogrammetry: A low-cost, effective tool for geoscience applications. Geomorphology 179: 300-314. doi:10.1016/j. geomorph.2012.08.021.

Williams, S.C.P. 2013. Studying volcanic eruptions with aerial drones. PNAS 11027: 10881. doi:10.1073/pnas.1309922110.

Xie, Z., J. Yang, C. Peng, Y. Wu, X. Jiang, R. Li, Y. Zheng, Y. Gao, S. Liu, and B. Tian. 2014. Development of an UAS for post-earthquake disaster surveying and its application in Ms7.0 Lushan Earthquake, Sichuan, China. Comput. Geosc. 68: 22-30.

Yajima, R., Nagatani, K., Yoshida, K. 2014. Development and Field Testing of UAVbased Sampling Devices for Obtaining Volcanic Products. IEEE ISSRR: 1-5. DOI: 10.1109/SSRR.2014.7017680.

\section{Submit your manuscript to a SpringerOpen ${ }^{\circ}$ journal and benefit from:}

- Convenient online submission

- Rigorous peer review

- Immediate publication on acceptance

- Open access: articles freely available online

- High visibility within the field

- Retaining the copyright to your article

Submit your next manuscript at $>$ springeropen.com 